\section{Gala Fult: The first Uruguayan apple cultivar}

\section{Maximiliano Dini ${ }^{1,2}$, Danilo Cabrera ${ }^{1}$, Pablo Rodríguez ${ }^{1}$ and Roberto Zoppolo ${ }^{1^{*}}$}

\begin{abstract}
Gala Fult is the first Uruguayan apple cultivar, originated by spontaneous somatic mutation of 'Royal Gala', identified and evaluated by nurseryman Fernando Rocca and INASE. The fruits have a complete red-blushed skin without streaks and matures more precociously than the other 'Gala' clones, but with the same range of edaphoclimatic adaptation.
\end{abstract}

Keywords: Malus domestica Borkh., apple breeding, new apple variety.

\section{INTRODUCTION}

Apple (Malus domestica Borkh) is one of the most planted deciduous fruit trees in the world, with more than 89 million tons produced in 2016, encompassing $5,293,340$ hectares (FAO 2018).

Gala cultivar was obtained by J. H. Kidd in 1934, in New Zealand, as a result of the hybridization between 'Kidd's Orange Red' and 'Golden Delicious'. The 'Gala' name emerged in 1962 but was launched only after 1965 for its commercial plantation. However, it wasn't very popular until the mid-70's when several cultivars with red overcolor appeared. 'Royal Gala' was the first clone to appear within this group. It has been widely planted in recent decades in both hemispheres, especially in New Zealand, Brazil, Argentina, Chile, Australia, China, Europe (especially France), and USA (Worraker and Withnall 1997, Hampson and Kemp 2003, Blanke 2013, Toranzo 2016).

Lack of red overcolor is one of the main reasons for discarding fruits and causes direct and indirect economic losses. Overcolor development is determined by genetic and environmental factors. Among these, light, temperature, and relative air humidity are the most reported to influence the development of the red color. The percentage of overcolor is one of the critical criteria in commercialization. Therefore, this parameter is one of the main characteristics considered in the selection of new fruit clones (Iglesias et al. 2000, De Angelis 2010).

Apple is one of the main deciduous fruits species grown in Uruguay. The selection of early and intensive red varieties in Uruguay is one of the driving characteristics in the selection process conducted by the Instituto Nacional de Investigación Agropecuaria (INIA) and other actors. Thus, a different tree was detected in 2002 by Agronomist Fernando Rocca, owner of "Los Sauces" nursery. This tree was studied by F. Rocca and included as Gala Fult cultivar in the National Register of Cultivars of the Instituto Nacional de Semillas (INASE) of Uruguay, in 2008.
Crop Breeding and Applied Biotechnology 19: 135-140, 2019 Brazilian Society of Plant Breeding. Printed in Brazil http://dx.doi.org/10.1590/198470332019v19n1c19 \section{(n)}


In this context, the purpose of this study is to inform growers, nurseries, and the scientific community about the characteristics of the first Uruguayan apple cultivar Gala Fult.

\section{CULTIVAR ORIGIN AND DEVELOPMENT}

In 2002, Agronomist Fernando Rocca, owner of "Los Sauces" nursery, found a spontaneous somatic mutation of Royal Gala cultivar. This occurred in a commercial 'Royal Gala' apple orchard in Paso del Bote (lat 34 36' 40.20” S, long 56 26' 33.15" W, and alt $14 \mathrm{~m}$ asl), Canelones, Uruguay. The main reasons for its selection were its early maturation and the smooth and entirely red coloration of the fruit epidermis.

Table 1. Characteristics of the Gala Fult apple cultivar according to UPOV descriptors

\begin{tabular}{|c|c|c|c|c|c|}
\hline \multicolumn{2}{|c|}{ Characteristics } & \multirow{2}{*}{$\begin{array}{c}\text { UPOV }^{1} \\
1\end{array}$} & \multirow{2}{*}{$\begin{array}{c}\text { Classification } \\
\text { medium }\end{array}$} & \multirow{2}{*}{$\begin{array}{l}\text { Example varieties } \\
\text { Golden Delicious }\end{array}$} & \multirow{2}{*}{$\begin{array}{c}\text { Note } \\
5\end{array}$} \\
\hline \multirow{4}{*}{ 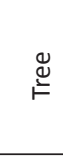 } & Vigor & & & & \\
\hline & Type & 2 & ramified & Elstar, Golden Delicious & 2 \\
\hline & Habit & 3 & spreading & Bramley's Seedling, Jonagold & 2 \\
\hline & Type of bearing & 4 & on spurs and long shoots & Jonagold & 2 \\
\hline \multirow{2}{*}{$\stackrel{4}{\stackrel{\pi}{9}}$} & Attitude in relation to shoot & 10 & outwards & Bramley's Seedling & 2 \\
\hline & Incisions of margin & 15 & serrate type 1 & Elstar, Gala & 3 \\
\hline \multirow{2}{*}{ 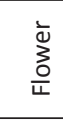 } & Arrangement of petals & 21 & overlapping & Schone van Boskoop & 3 \\
\hline & Position of stigmas relative to anthers & 22 & above & Golden Delicious & 3 \\
\hline \multirow{16}{*}{ : } & Size & 24 & medium & Cox's Orange Pippin & 5 \\
\hline & Height & 25 & medium & James Grieve & 5 \\
\hline & Diameter & 26 & medium & Golden Delicious & 5 \\
\hline & Ratio height/diameter & 27 & medium & Jonagold & 5 \\
\hline & Size of eye & 31 & medium & Cox's Orange Pippin & 5 \\
\hline & Length of sepal & 32 & medium & Alkmene & 5 \\
\hline & Bloom of skin & 33 & moderate & James Grieve, Jonathan & 2 \\
\hline & Ground color & 35 & yellow & Delorgue, Gala, Transparente de Croncels & 3 \\
\hline & Hue of over color & 37 & purple red & Red Jonaprince, Spartan & 4 \\
\hline & Intensity of over color & 38 & dark & Red Jonaprince, Spartan & 7 \\
\hline & Pattern of over color & 39 & only solid flush & Red Jonaprince, Richared Delicious & 1 \\
\hline & Area of russet around stalk attachment & 41 & medium & Alkmene & 2 \\
\hline & Area of russet on cheeks & 42 & absent or small & Golden Noble & 1 \\
\hline & Area of russet around eye basin & 43 & absent or small & Golden Noble & 1 \\
\hline & Color of flesh & 53 & cream & Jonagold & 2 \\
\hline & Aperture of locules & 54 & fully open & Mclntosh & 3 \\
\hline \multirow{3}{*}{ 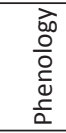 } & Time of beginning of flowering & 55 & early & Idared, Schone van Booskoop & 3 \\
\hline & Time for harvest & 56 & $\begin{array}{l}\text { very early to } \\
\text { early }\end{array}$ & $\begin{array}{c}\text { Vista Bella } \\
\text { Discovery, Jerseymac, Sunrise }\end{array}$ & 2 \\
\hline & Time of eating maturity & 57 & very early to early & White Transparent & 2 \\
\hline
\end{tabular}

${ }^{1}$ UPOV codes (International Union for the Protection of New Varieties of Plants) protocol number (UPOV 2006). 
After selecting the mother plant, four generations of grafting were done to ensure the stability of the mutation. To evaluate the new cultivar, we installed two parcels to determine distinctness, uniformity, and stability, in 2003. For both parcels, the 'Gala Fult' scions were over grafted on two-year-old apple trees with three different rootstocks (M7, M9 Pajam 2 and MM106). Forty plants were over grafted per rootstock. Apple trees were trained to two or three main leaders in North-South oriented rows, $4 \mathrm{~m}$ apart, with trees within the row at $1 \mathrm{~m}$ for M9 Pajam 2 and $2.25 \mathrm{~m}$ for M7 and MM 106, resulting in a density of 2,500 and 1,111 plants per hectare, respectively. Tests were conducted in "Los

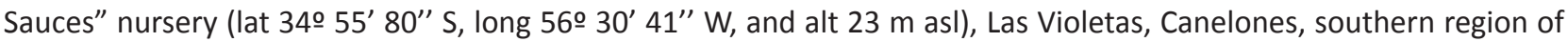
Uruguay and in Barros Blancos (lat 34 44' 01" S, long 55 58' 40” W, and alt 25 m asl), Canelones, Uruguay. This last was monitored by INASE.

Both trials were evaluated from 2004 to 2007, presenting a positive result for the three aspects: distinctness, uniformity, and stability. We also evaluated the vegetative and reproductive expression of these trees, observing its distinct characteristics of early harvest and entirely red colored fruits. The main characteristics of the tree, leaf, flower, fruit, and phenology were classified using the protocol described by the International Union for the Protection of New Varieties of Plants (UPOV 2006) and are available in Table 1. After the third year of harvest, on February 13, 2007, the application for the cultivar protection in the country of origin was made at the National Register of Cultivars of INASE of Uruguay. The title deed was granted on November 21, 2008, under registration number 2, with a due date of November 20, 2033.

\section{CULTIVAR CHARACTERISTICS}

\section{Plant description}

'Gala Fult' trees have medium vigor and growth habit with good branch angles (Figure 1A). Leaves are morphologically equal to other cultivars of the 'Gala' group, but pedicel, sepals, and pistil are distinctively reddish. Flowering is comparable to other 'Gala' clones and occurs during the first week of October (Southern Uruguay), with an estimated period of 100 days from full bloom to harvest. Pollination is recommended with 'Granny Smith', 'Cripps Pink' or any pollinators used

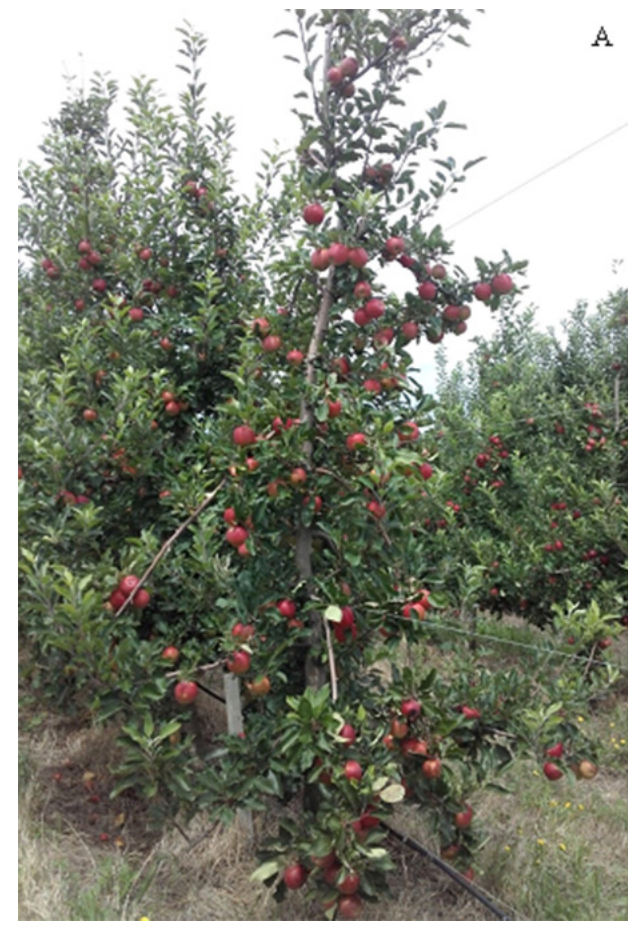

A

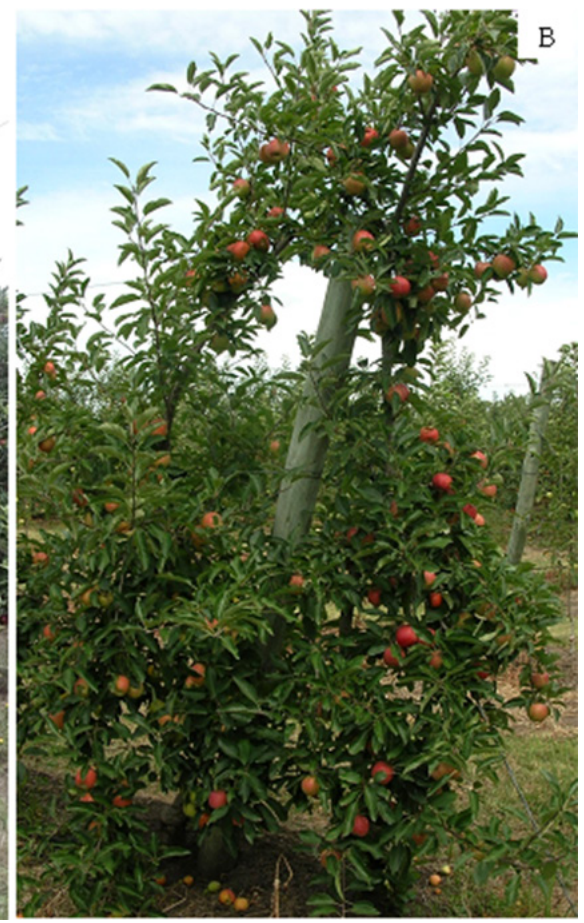

Figure 1. 'Gala Fult' tree on M9 rootstock, open branch angles, productive, and with well colored fruit (A) compared to the 'Royal Gala' tree on $\mathrm{M9}$ rootstock (B). 

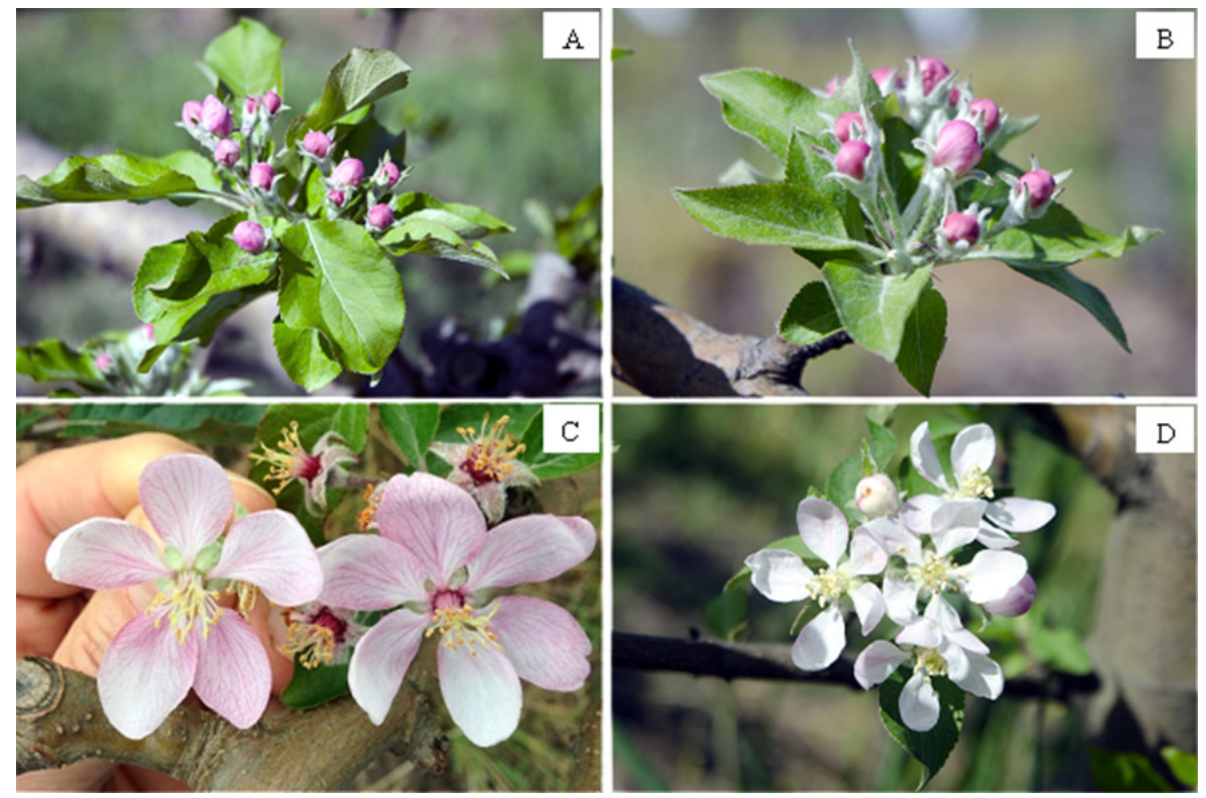

Figure 2. 'Gala Fult' flowers in balloon stage (A) compared to the 'Royal Gala' flowers in balloon stage (B); 'Gala Fult' flowers (front right and background), with the violaceus base of its stamens, pedicels and sepals compared to Cripps Pink flower (front left) and (C) to the 'Royal Gala' developed flowers (D).

for the Delicious cultivars group. It has a medium to high percentage of fruit set, so it requires the chemical thinning of flowers and fruits. Fruits ripen in mid-January, approximately ten days before other 'Gala' clones.

\section{Flower description}

'Gala Fult' flowers are of a predominantly dark pink coloration at balloon stage, similar to 'Royal Gala' and other 'Gala' clones (Figures 2A and 2B). Petals are overlapping until shortly before petal fall, and styles are longer than the stamens, with stigmas located above the anthers. A particularity of 'Gala Fult' when compared to other 'Gala', clones and other cultivars is the violaceus coloration of the base of its stamens and sepals, which turns more visible after full bloom and during the petal fall stage (Figures 2C and 2D).

\section{Fruit description}

'Gala Fult' fruits are generally conical without ribbing. The epidermis presents a yellow ground color, and approximately 90-100\% of the fruit surface develops a dark purple-red blush (Figures $3 \mathrm{~A}$ and $3 \mathrm{C}$ ), which is one of its highlighted features. There is no development of stripes. Fruit height and equatorial diameter are average, approximately $5.9 \mathrm{~cm}$ and $6.7 \mathrm{~cm}$, respectively, with a certain variation according to orchard management and climatic conditions. The flesh is

Table 2. 'Gala Fult' fruit characteristics in first pick harvest, average values for years 2011 to 2018

\begin{tabular}{lcc}
\hline Fruit characteristics & 'Gala Fult'/M9 rootstock & 'Gala Fult'/M7 rootstock \\
\hline Surface red color (\%) & 93 & 92 \\
Soluble solids content ('Brix) & 12.91 & 12.30 \\
Fruit weight (g) & 142 & 138 \\
Flesh firmness (N) & 77.62 & 72.90 \\
lodine-starch index & 5 & 5 \\
Start date of ripening* & & January 21 \\
Finish date of ripening* & & February 02 \\
\hline
\end{tabular}

* Without the application of budbreak promoters. 

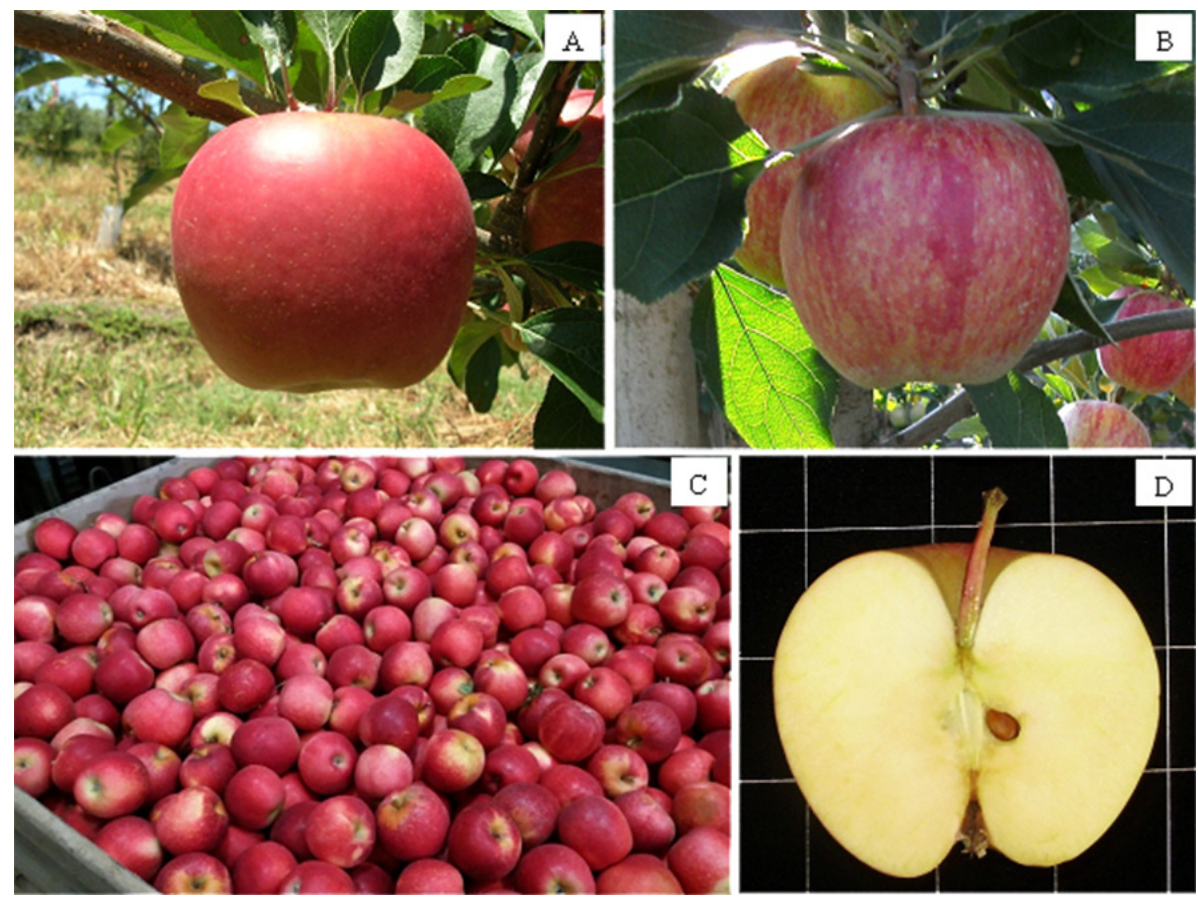

Figure 3. 'Gala Fult' fruit with its particular red color without stripes (A) compared to 'Royal Gala' fruit (B); 'Gala Fult' fruits harvested (C); 'Gala Fult' flesh color and full opening of the locules (D).

firm (70 to $80 \mathrm{~N}$ ) and cream colored with a full opening of the locules (Figure 3D). At harvest, the soluble solids content reaches values between 12.5 and $14.0^{\circ}$ Brix, comparable to other 'Gala' clones such as 'Baigent', but with more than $94 \%$ of red colored skin.

\section{PERFORMANCE}

\section{Production and adaptation}

The National Program of Research in Fruit Production of the Instituto Nacional de Investigación Agropecuaria (INIA) of Uruguay, in agreement with the "Los Sauces" nursery since 2009, has been conducting the agronomic evaluation

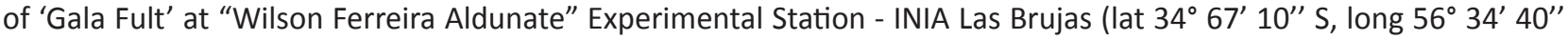
$\mathrm{W}$, and alt $22 \mathrm{~m}$ asl). An experimental trial was installed to evaluate the agronomic behavior of Gala Fult cultivar on M9 and M7 rootstocks (Cabrera and Rodríguez 2013). The results indicate that the Gala Fult is a precocious cultivar, that produces in well-exposed, young fruiting structures and, in a lesser proportion, the fruit is observed on terminal buds (Figure 1A). Fruit is harvested in 2 or 3 picks, presenting earlier maturation in trees on M9 rootstock and similar quality characteristics (Table 2). The yield in 2018 (ninth leaf) for the evaluated combinations reached 43 and 52 tons per hectare with trees on $\mathrm{M} 9$ and $\mathrm{M7}$, respectively, which is considered the highest yield reached until the moment, still with possibilities of growth. 'Gala Fult' seems to have similar chilling requirements when compared to the 'Baigent' clone according to the phenological behavior observed.

\section{PROPAGATIVE PRODUCTION MATERIAL}

Gala Fult apple cultivar, obtained by the "Los Sauces" nursery (INASE № 1631) in November $21^{\text {st }}, 2008$, is included in the National Register of Cultivars of INASE - Uruguay, under the number 373. According to the Resolution N ${ }^{\circ} 104-108$, under Law N¹6811, under Decree 438 04, the 'Gala Fult' of the M. domestica Borkh. species, of common name apple in favor of Agronomist Fernando Artigas Rocca Lugano, is protected. 


\section{Dini et al.}

This cultivar was also registered and protected by the Ministry of Agriculture, Livestock and Supply (MAPA), National Service of Protection of Cultivars $\left(N^{\circ} 20170180\right)$ of Brazil and it is in the process of registration in the Community Plant Variety Office (CPVO) from Europe.

\section{ACKNOWLEDGEMENTS}

The authors thank Fernando Rocca, Los Sauces nursery, INASE and INIA Las Brujas.

\section{REFERENCES}

Blanke M (2013) 'Gala' and 'Fuji': Brazil's apple production with two varieties among ancient araucaria trees and agroforestry, fusing with nature. Erwerbs-Obstbau 55: 87-93.

Cabrera D and Rodríguez P (2013) Evaluación de la primera variedad de manzana uruguaya 'Gala Fult': roja, crocante, jugosa y temprana. Revista INIA 33: 55-58.

De Angelis V (2010) Factores que influyen en el color de las manzanas. Fruticultura \& Diversificación 62: 12-17.

FAO (2018) FAOSTAT. Available at: <http://www.fao.org/faostat/ en/\#data/QC/>. Accessed on Feb 19, 2018.

Hampson CR and Kemp H (2003) Characteristics of important commercial apple cultivars. In Ferree DC and Warrington IJ (eds) Apples; botany, production and uses. CABI, Wallingford, p. 61-89.
Iglesias I, Carbó J, Bonany J, Dalmau R, Guanter G, Montserrat R, Moreno A and Pages J (2000) Manzano; las variedades de más interés. IRTA, Barcelona, 240p.

MGAP.DIEA (2016) Encuesta frutícola de hoja caduca; zafra 2016. Available at: <http://www.mgap.gub.uy/sites/default/files/ encuesta_fruticola_de_hoja_caduca_zafra_2016_1.pdf $>$. Accessed on Feb 19, 2018.

Toranzo JO (2016) Producción mundial de manzanas y peras. INTA, Rio Negro, 39p.

UPOV (2006) International Union for the Protection of New Varieties of Plants; Apple (Fruit Varieties). Available at: <http://www.upov.int/ edocs/tgdocs/en/tg014.pdf/>. Accessed on Feb 10, 2018.

Worraker R and Withnall M (1997) Royal Gala in England; a grower's guide to improve production. Malcolm Whitnall, West Malling, 112p. 